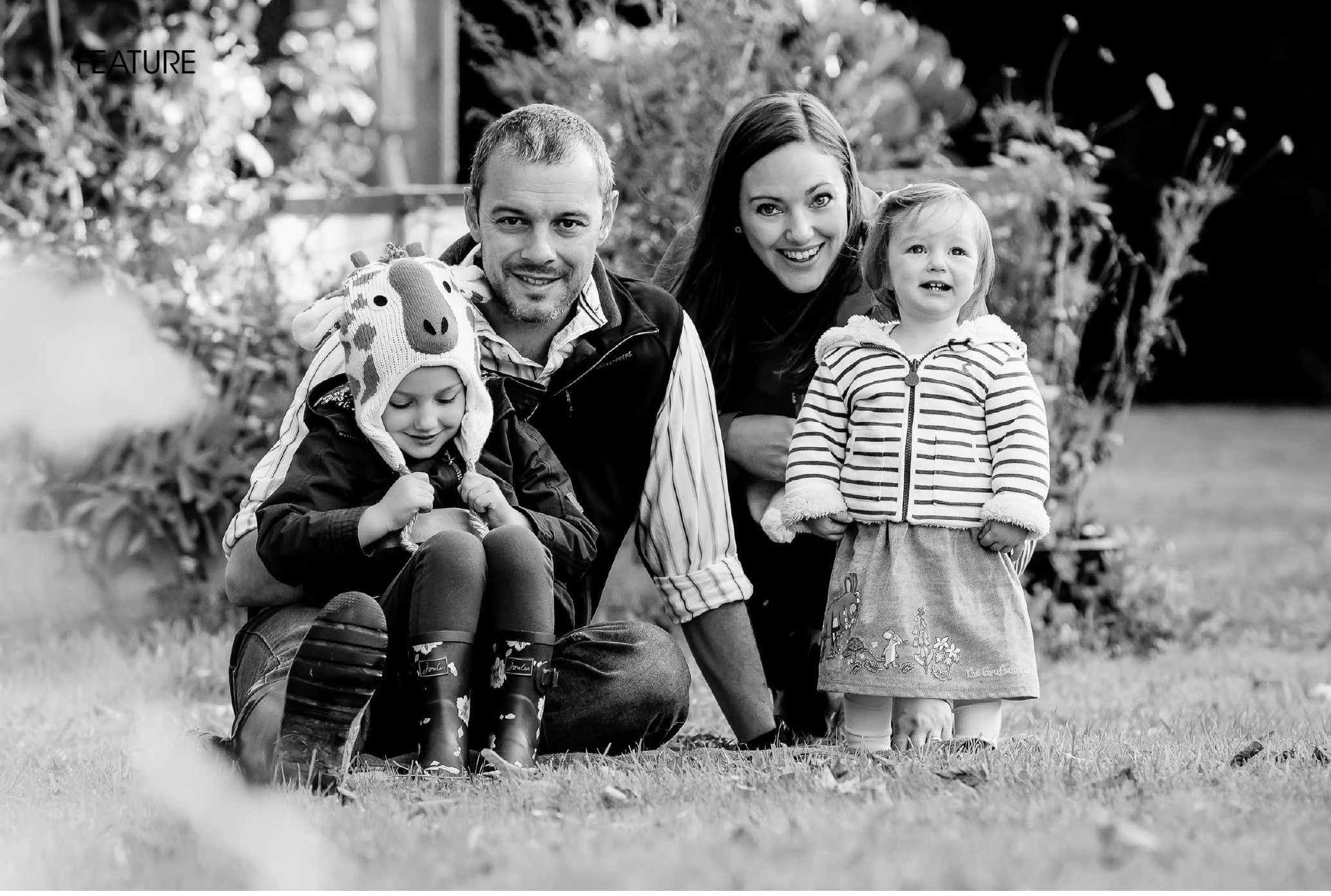

\title{
Sarah Hill: a wild card now speaking up for DCPs
}

Dental hygienist Sarah Hill was recently appointed DCP Board Observer for the Faculty of General Dental Practice UK (FGDP[UK]), succeeding the late Janet Goodwin. Kate Quinlan spoke to Sarah about her appointment and her career to date.

\section{Background}

Sarah qualified as a dental hygienist from the University of Bristol, with distinction, in 2012, and also holds a BSc (Hons) in Biomedical Sciences from the University of Southampton and a Postgraduate Diploma in Clinical

Education from the University of Plymouth.

Sarah works as a hygienist in a Mixed (NHS/Private) General and Orthodontic practice in Halesowen; delivers oral health presentations on behalf of $\mathrm{TePe}$; is an assessor for the National Examining Board for Dental Nurses (NEBDN); is an active member of the British Society of Dental Hygienists and Therapists (BSDHT); and is married with two daughters.

Note: The Faculty of General Dental
Practitioners (UK) will be transferred to the College of General Dentistry (CGDent), a new independent college representing the interests of primary care dentistry, by June 2021.

\section{Interview}

What were your career plans when you were still at school?

It was actually to study medicine to become a doctor. Unfortunately, I didn't achieve the A level grades that I needed to so I went through clearing to study biology at the University of Southampton. During the first year, I changed to biomedical sciences as the modules are exactly the same, but basically, biomedical sciences didn't include the study of plants.

I enjoyed biomedical sciences and thought that it would give me a good grounding if I wanted to apply for medicine again.

What were your next steps once you graduated?

I ended up with a 2:2 so I didn't apply for medicine, and I was a bit unsure as to what to do at the time. Then I got through to an interview with an agency to become a sales representative with GlaxoSmithKline (GSK) in London. I wasn't successful the first time around, but then for some reason, I got a phone call a couple of days later saying they would like to take me on. So I moved to London with a few days' notice.

I essentially became a sales rep selling the flu vaccine, followed by the cervical cancer 
vaccine. And then I moved on to another pharmaceutical product as well, which took me to Bristol meaning that I was covering a huge area from South Wales all the way to Swindon and from Worcestershire down to North Somerset as well.

It was a really good experience, but then I had the opportunity to apply to dental hygiene at Bristol University and was accepted.

So, we decided to buy a house in Bristol and my husband commuted to Portsmouth while he was training to be a nuclear engineer in the Royal Navy.

\section{So you didn't have any dental} experience before applying to study dental hygiene?

Well, this will tell you a bit about me really. Basically, you could say I was born into dentistry. Both my parents are dentists which I don't tend to tell too many people - but they own the practice that I am working in today.

I promised that I would never have anything to do with dentistry, because I wanted to stand on my own two feet. Obviously, my parents used to come home and talk about dentistry all the time and I saw the less glamorous side of it. And I said, no, I'm not going to get involved in it. But I was a receptionist for a long time and really enjoyed it, and still do now, and I did a bit of chairside before dental nurse registration came in if I needed to help out. But I didn't actually work as a dental nurse before studying to become a dental hygienist. So I was a bit of a wild card in my group at university.

Why did you decide at that point that you'd like to be a hygienist?

I think it was the clinical aspect. When I was working as a sales rep for GSK, I found it quite lonely. It involved a lot of driving and I missed being with people and wanted to use my science and apply it clinically. I'd always wanted to do a clinical job, from the beginning - be with patients, interact with them and make decisions. One of my dental hygienists when I was younger, who used to work at this practice, always seemed to love her job as well. So I just wanted to see if I could get in, and I did.

\section{Did you enjoy the course?}

Yes, I absolutely loved it; it was the best decision I've ever made. I ended up coming out with a distinction from the University of Bristol. The type of teaching suited me, the ethos they had, the professionalism, the balance with clinical time, and also the academic staff as well: it was all really good. Bristol is a prestigious dental school to be part of and I thoroughly enjoyed it. It was very, very tiring, but it was great and I really enjoyed it.

\section{Can you outline your career history since graduating?}

As soon as I graduated my husband was then posted down to Plymouth. So we decided to move to married quarters in Plymouth. I followed him to support his career.

I applied for jobs and worked in Newton Abbot, Totnes and Tavistock in mixed private and NHS practices, which was really good
Then in December, I got the DCP Observer role with the FGDP.

It sounds like you've been very active outside your day job. Do you thrive on a busy schedule and lots of varied activities?

Yes, I always think if you want something done, ask a busy person. I do love being busy, but it does mean I have to be very organised. I love lists!

You do of course have to get the balance right, juggling everything with home life. Sometimes I can get the balance wrong and have to reset myself.

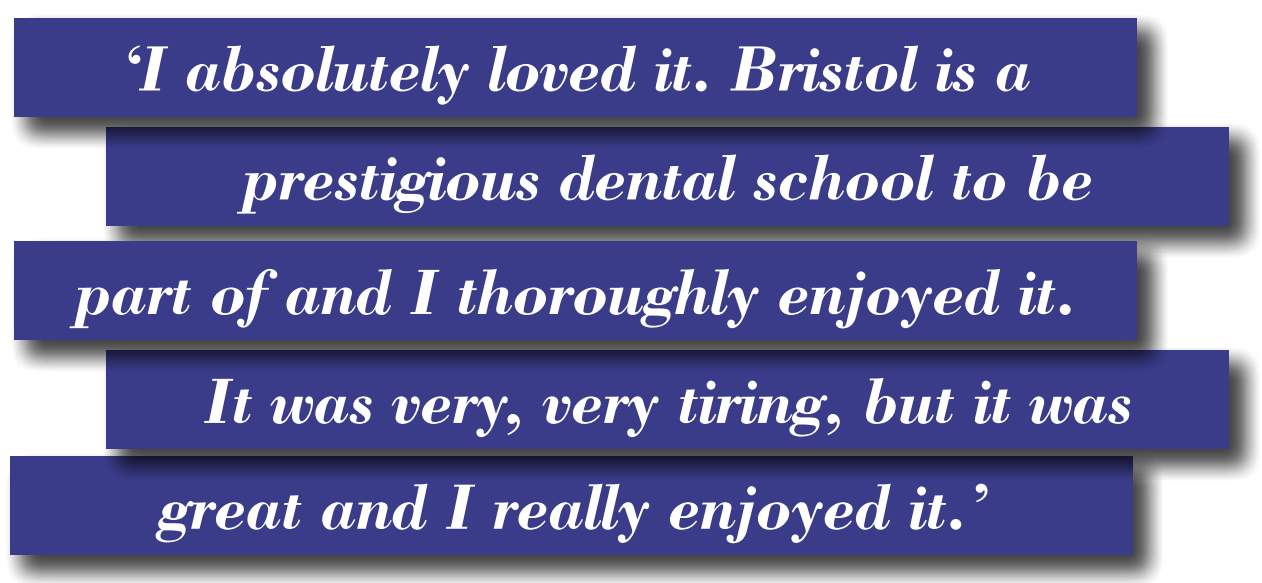

experience. I also commuted to the family practice in the Midlands once a month to carry out hygiene work.

I then saw an advert for a lecturer in community based dentistry at Plymouth University. So I applied for it and they actually wanted a dual hygienist and therapist, which I wasn't. But I was given the role as a job share with my colleague and now friend. It was a huge undertaking in terms of clinical supervising and looking at community based projects with the students. Again, it was really great experience.

Our first child was born in 2016, so I took a little break, and then we decided to relocate back to the West Midlands.

In 2017 I took on the role with $\mathrm{TePe}$ $\mathrm{UK}$ as part of their extended clinical team, going to conferences, being on the stand and talking about the products. I also joined the educational team, going to universities and delivering presentations based around TePe products and providing oral hygiene instruction.

Since then I have had another child and had another break, and then I came back to work and within about eight weeks the pandemic started.

Towards the end of 2020 I became an NEBDN assessor as part of Learn Direct.
How have you been affected generally by the pandemic over the last year?

I think it's been unsettling for everybody. At the start of the pandemic, as I mentioned, I had just returned from maternity leave into my clinical job. My husband had just left the Navy after ten years and was about to start a new job, and nursery closed for the children as well. All of my self-employed work fell off the edge of a cliff, and there was a bit of a time lag between dentistry ceasing and working out the furlough scheme.

I must say, I'm extremely lucky that I'm an employed dental hygienist at this practice. A lot of my colleagues are self-employed.

It was lovely to be at home as well, and enjoy time with the family - but it was of course tiring keeping a four-year-old and a one-year-old occupied and happy. It was really difficult not seeing friends and relatives as well.

At the practice we stopped seeing patients on 23 March 2020. I remember it very well - I can't believe it's almost a year - and we reopened on 8 June. Since then we have been seeing patients and everyone has done an amazing job of pulling together and working as a team.

I think this period has affected everybody 
mentally. I see that with my patients, when they walk through the door. I will ask them how they are and I can see it in their faces... I often have patients who just cry as it's a bit of a release and sometimes we are the only people they have seen for weeks and months. I think that's quite sad really but I'm glad we can be there for them.

My dental nurse and I have taken a lead role in looking after our colleagues' wellbeing. We've made pamper packs, treat boxes and held a virtual cocktail party at Christmas.

In the early days of the pandemic there was a lack of communication for dental practice staff, and that was

really awful, because I think it stirred up a lot of anxiety in everybody. Things were going quite wild on social media groups, causing quite a frenzy. So my dental nurse and I thought we would take charge of that and try and communicate well with colleagues and with patients.

\section{Was the role of DCP Board Observer} something you were nominated for, or something you applied for?

It's something I applied for. I saw an email that came into my inbox from the FGDP(UK), advertising for a new DCP Board Observer to replace Janet Goodwin, who sadly died last year. I applied for it and didn't think I'd get it in the slightest. I sent across my CV and I got a Skype interview. I was amazed to be offered the position.

\section{What does the role involve?}

There are four meetings a year and of course everything has been virtual so far. As I'm a Board Observer I can't vote, and I'm an associate member of the FGDP, not a full member. Essentially, I observe board meetings and have to wait to be asked to speak. I think you can raise an issue, but generally you're there to observe, raise any concerns or questions at any point, and be a voice for DCPs.

I spoke to Ian Mills, the Dean of the FGDP, in February, to talk about the role, and then we had our first board meeting last Friday which was really interesting. I worked with
Ian down in Plymouth and Abhi Pal, who has just been appointed the new Dean of FGDP, used to be my boss so I know him well.

It is early days but I did have a meeting with the British Association of Dental Nurses (BADN) because they're keen to collaborate.
I think there are a lot of issues to consider, such as scope of practice of the dental team and ensuring that all members of the dental team understand everyone else's scope of practice. Looking at pay scales - that is always something that crops up.

(BADN) because they're keen to collabore. something hat crops up. 
One thing the pandemic highlighted is that in mixed or NHS practices, ie, if the dentist has an NHS contract, the dentist or dentists will receive all the NHS benefits, but the rest of the dental team don't receive any. Yet when the pandemic started, everyone who worked in an NHS practice or had an NHS contract was called on to be redeployed.

There are numerous other issues to explore such as exemptions and prescribing for dental hygienists and therapists; mentorships and career pathways; oral health inequalities and NHS contracts.

Overall, I am passionate about educating the dental team, learning from each other, and inspiring and supporting those dental professionals who are still in training or about to qualify or graduate, as they embark on their careers in dentistry.

\section{What are your thoughts on how} dentistry will ever recover from the effects of the pandemic? Do you think NHS dentistry will 'catch up' with all the patients who have missed appointments?

Very, very good question. I think the picture is extremely varied across mixed and NHS practices around the country. I feel like I can only really talk about my own perspective. I have heard some horror stories of, you know, patients having to pay private fees in other places. In this practice, I think the team have managed very well with seeing patients through teamwork, but it hasn't been easy. The oral health and wellbeing of our patients has been at the forefront of this.

We stopped face-to-face treatment on 23 March 2020, and began again on 8 June. In between that time, we had a triage system; dental nurses and the dentist triaged and spoke to patients and sent out information in the post to try and reassure them during that very unsettling time when we couldn't see them. We began to see patients again on 8 June and some practices haven't and as I said, since we've been seeing patients again, sometimes that has been the only contact patients have had with other people for weeks or months. It's had a huge impact on all of the dental team, and of course we have all had to cope with the PPE and the extra cleaning in between patients and so on.

Three of our dental nurses have become COVID-19 vaccinators, which is brilliant. Looking forward, we've got the vaccine, we've got the lateral flow tests that are in place, we've got the PPE and we've been fit tested: we're in a much better place.

I think at this practice, if we sing our own praises, we've cracked it. We're even seeing a lot of new patients that we wouldn't normally have seen, because a lot of the practices around here are still closed. A lot of these patients are worried about their oral health.

In answer to your question: I don't know if NHS dentistry will ever catch up. There were oral health inequalities before the pandemic and the gap has now got even larger. enjoying eating the vegetables and teaching the children where food comes from.

I've probably eaten too much cake over the lockdown though!

What do you look forward to doing when the lockdown restrictions are relaxed and eventually removed?

\section{'One thing the pandemic highlighted is} that in mixed or NHS practices, ie, if

\section{the dentist has an NHS contract, the} dentist will receive all the NHS benefits

\section{but the rest of the dental team don't'}

Do you work full time as a dental hygienist at the moment?

No, I just work Mondays and Friday mornings clinically. I stopped working at a number of other practices after maternity leave, because the hours weren't quite right. I am also writing a radiography course for Learn Direct at the moment, and doing TePe presentations. So I work two days a week and on these days my daughter is allowed to go to school, and on the other three days I homeschool.

I have always respected teachers but now I have a huge respect for teachers. I don't know how they do it; give me dentistry teaching any day! I'm not sure I'm cut out for early years phonics, maths and reading.

My husband was able to start his new job in April last year and has been working from home ever since, which has been rather a change for us, and he is a keyworker also.

Our younger daughter attends nursery on the two days I am working.

\section{What do you like to do outside of work and to relax?}

I love baking, that is one of my favourite things to do - a little bit controversial, being a hygienist. Spending time with the family, photography, singing, musicals, playing the piano. I love spas, when they're allowed.

\section{Are you strict with your children's diets?}

I would say everything in moderation; we like to cook as much from scratch (and homegrown/local) as we can.

On the first lockdown my husband built a vegetable patch in the garden so we have been
I would say I am most looking forward to enjoying watching my children play together with their friends outside, in the warm sunshine, and having a picnic.

I'm really looking forward to seeing my friends, not just on Zoom; hugging my best friend, but also enjoying time with my family and my Mum's roasts, because they're the best thing in the world.

Do you cross paths with your Mum at work?

No because she works different days to me, unless we have staff training together. She works Tuesday, Wednesday, Thursday, and I work Mondays and Friday mornings. We have had a hug in PPE!

My Dad retired clinically about ten years ago but still owns the practice.

\section{Anything else to add?}

I'd just like to say thank you to you for giving me the time to talk about my passion for dental hygiene. It hasn't been a particularly easy path to get to where I am now but with determination and the support of family and friends, I've managed it.

I'm extremely glad to work as part of my very supportive dental team in my clinical job but also feel that my dental colleagues have become unified during the pandemic and really supported each other. My only hope is that this continues and that I can do a good job of being a voice for DCPs across the country.

https://doi.org/10.1038/s41407-021-0550-y: 